\title{
The Importance of Using Metaphors in Foreign Language Teaching and Learning
}

\author{
Behçet Çelik ${ }^{1}$ \\ ${ }^{1}$ Department of Language Teaching, Tishk International University, Erbil, Iraq. \\ Email: behcet.celik@tiu.edu.iq
}

DOI: $10.53103 /$ cjlls.v1i2.17

\begin{abstract}
So far various studies on language teaching and learning have been conducted to explore the teachers' perceptions of their professional practice. However, there are only a few of them focus on student-produced metaphors related to the process of foreign language. Researchers have studied how teachers' metaphors affect their methods and strategies in order to understand the complex processes of teaching in a classroom environment. Metaphors not only include crucial information about teachers' growth as professionals but also reveal their educational values, beliefs, and principles. Personal beliefs play a significant role in teachers' classroom practice, which are the result of their self-construction. This study attempts to explain the importance and effectiveness of using metaphors in foreign language teaching and learning. 52 university students in the department of Teaching Mathematics and Turkish attending in the 1st class in Gazi University Faculty of Education, Ankara, in Turkey. With the help of content analysis, we tried to investigate students' attitudes towards English course by using metaphors. While a conceptual metaphor program is being designed in this study, we found out that figurative language is not incidental but omnipresent in daily language. This ubiquity of metaphors and idioms is concerned with the high proficiency of figurative language. The results of the study indicate that metaphor awareness of understanding idiomatic expressions is highly significant in foreign language.
\end{abstract}

Keywords: Metaphor, English, Foreign Language, Turkey

\section{Introduction}

As a literal meaning, a metaphor is described as a 'figure of speech' used to give a special effect. Moreover, two types of figures of speech are mentioned: simile is described as something compared to something else by using a function word such as 'like' or 'as'. Metaphor uses no function words; instead, one notion is described by another notion'. 

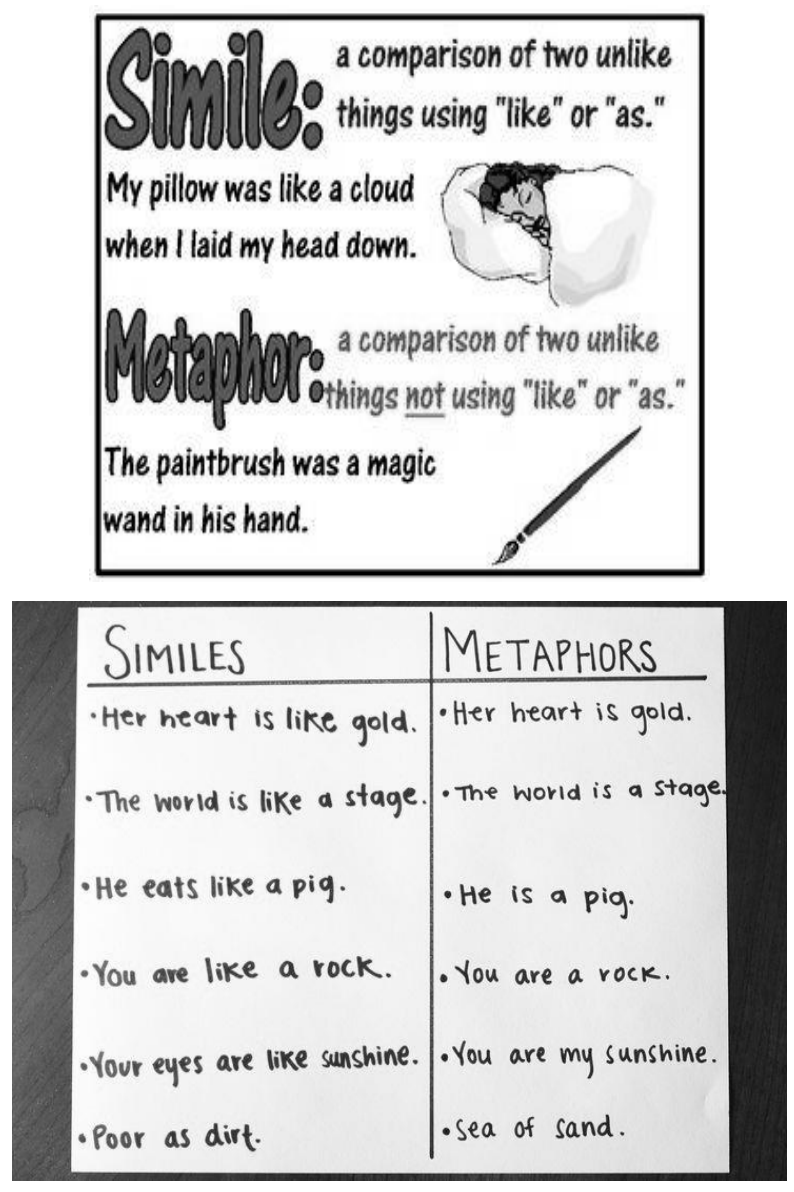

Figure 1: Some similes and metaphors

Metaphors have been extensively used in poetry in the past but in the recent years it has also been used in second language acquisition. For instance, when Shakespeare's Romeo says "Juliet is the sun", we can understand her personality as pretty, positive and bright. This metaphor shows that; Juliet is as important as the sun for Romeo. With the impact of Lakoff and Turner (1989), the meaning of metaphors has changed their origin by becoming 'unconscious and automatic'. Metaphors are "important tools of cognition and communication" (Ortony \& Fainsilber, 1989, p. 181). Metaphors not only constitute our thinking but guide our actions (Lakoff, \& Johnson, 1980; Richards, 1936). Metaphors act as a screen, through which the metaphoric subjects are seen. They facilitate the way people try to perceive what goes on around them. They also help us formulate our thinking and our understanding of events. Therefore, the way teachers conceptualize their teaching experience can be examined by using metaphors. 


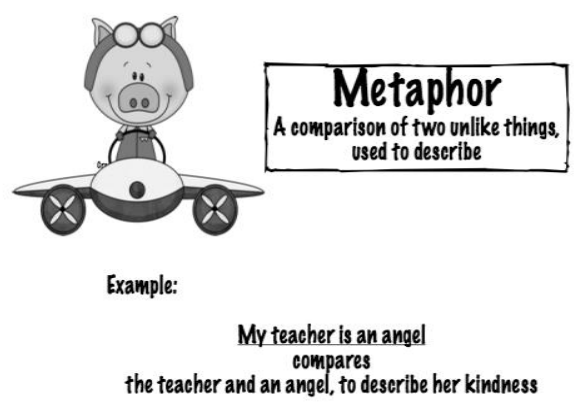

Figure 2: What is a metaphor?

Teachers' beliefs come from their self-instruction, which is piled up via culture, personal experience and education." (Xu, 2012, p.1398) Kelly (1995) suggests in his Personal Construct Theory, the teacher, like any individual, makes sense of his/her own world on the basis of his/her own personal experiences and constructs. Individuals are affected by constructs-cognitive structures formed as a function of background events and they can change their constructs at any time. On the basis of a constructivist view, it is likely that teachers' experiences change over time.

The need for articulating personal beliefs of teachers is of great importance for professional development but personal theories mostly exist at an implicit level; hence it becomes difficult to examine them. If teachers' beliefs and attitudes are not identified and examined, professional development can hardly be achieved. In general, metaphor acts as a symbolic language in which two different ideas or concepts are used to make comparison (Hansen, 2004 in Balim \& Çeliker, 2011, p.331). According to Lakoff and Johnson (1980), we can experience one kind of thing in terms of another by using metaphors. Besides, our thoughts and perceptions become more vivid and interesting with metaphors. When a metaphor is employed, the schema is transported from its customary realm to a new realm. As for the personal and professional development of teachers the challenge is to bring operating metaphors into consciousness awareness and to consider how metaphors could be encouraging or restricting growth (Bowman, 2007).

Metaphors are not just figures of speech, but constitute an essential mechanism of the mind allowing the modeling and reification of prior experience. With the increasing interest in the use of qualitative methods in examining teachers' beliefs, metaphors have widely been used to elicit personal theories of teachers (Balim \& Çeliker, 2011; Saban \& Keleşoğlu, 2011).

Metaphors have been used as a research instrument in a large number of studies in the fields of teacher education, teacher beliefs and reflection (Ak1ll \& Seven, 2010; Block, 
1992; Saban, 2004; Saban, Koçbeker, \& Saban, 2007; Tobin, 1990). In a study by Seferoğlu et al. (2009), metaphorical images of pre-service and in-service teachers as windows into their schemata for thinking about teachers were examined elaborately. The changes in teacher candidates' metaphorical images about classroom management in a social constructivist learning environment and concluded that most teacher candidates held a traditional teacher-centered view of classroom management before they were subjected to a constructivist curriculum practice.

In another study carried out by Cerit (2008) classroom teachers' metaphors about teachers have been investigated and it discovered that teacher is perceived as an individual who provides and disseminates knowledge for students. Çelikten (2006) stated that culture and teacher metaphors used in the educational system were explored by revealing that the teacher is usually seen as a doctor or a gardener.

Metaphors were also used by researchers to show the change that occurs in teachers' beliefs and attitudes (Tobin, 1990; Marshall, 1990). The studies emphasized that "a change in metaphors may indicate a change in how the world of teaching is conceived, a change in the evolving story of the self" (Bullough, 1991). Martinez, Sauleda and Huber (2001) investigated metaphorical conceptions of teachers regarding their images of learning and most of the metaphors were behaviorist and empiricist. Studies which used metaphors as the research tool in investigating teachers' beliefs and attitudes are not limited to teaching in the general sense.

Studies in the field of foreign language teaching also provided significant results and implied the power of metaphor as a research tool. In one of the studies in the context of language teaching and learning, Shaw, Barry and Mahlios (2008) explored English and foreign language teachers' metaphors and their connection with the conceptions of literacy. The findings of the study indicated that beliefs fall into nine themes including nurturing and guiding. In addition, Nikitina, Larisa \& Furuoka, Fumitaka (2008) collected samples of metaphors that students generated about language teachers, and it was found out that metaphors support the enlightened eclecticism approach toward language teaching.

Metaphors claim that 'human thought processes are metaphorical' and we use metaphors all the time, every day without even noticing. They represent our cognitive processes and our way of understanding and interpreting the world.

\section{Method and Procedures}

Based on the literature review, the research questions of this study include:

1. Can metaphors describe a student's state of mind?

2. What are students' perceptions regarding metaphors in language teaching and learning?

The study was carried out in the second semester in the academic year 2018-2019 
in Gazi University. Acknowledging convenience sampling, the subjects who participated in this study were attending the Foreign Language English II course in the department of Teaching Mathematics and Turkish in Faculty of Education.

\section{Participants}

52 university students in the department of Teaching Mathematics and Turkish attending in the 1st class in Gazi University Faculty of Education in 2018-2019. Their ages range from 18 to 21 . Females constituted $24 \%$ of the sample group $(n=24)$ with the remaining $16 \%$ being male $(n=8)$.

\section{Instrumentation}

Semi-structured interviews with volunteer students were undertaken to substantiate the essential findings of the content analysis. More precisely, thematic content analyses based on Neundorf (2002) have been made in order to measure psychological characteristics of individuals.

\section{Data Collection and Analysis}

"Learning is acquisition" is a metaphor that rooted in the behaviourist movement in psychology and supported by cognitive constructivist assumptions. The new knowledge is an outcome of transforming the old schemata into new ones. The aim of learning is "gaining possession over some commodity. Knowing is indistinguishable from "having" or "possessing". Two prominent educational metaphors view learning as "acquisition" or "participation". Both metaphors are important and serve as a "sense-making" tool (Sfard, 1998, p.12).

The students completed the sentence "Learning ENGLISH has been like..." with their own metaphors and provided a short explanation of the images. The students were given a short questionnaire with some sentence beginnings which they had to finish. These sentences became metaphors by which students described their imaginations. Subsequently, metaphors were compared to identify themes and topics, followed by student interviews to substantiate the survey results. Finally, frequency statistics were applied to analyze and inferences were made to report the results.

\section{Limitations}

The scope of the study is limited to university students and it can be argued that one of the limitations of this study is its small sample size. A second limitation derives from the gender imbalance generated, in this case, from the convenience sampling 
approach.

\section{Findings}

As to the findings of the study, total 26 metaphors were classified into 4 categories:

1. Metaphors that described learning in terms of a "journey", "travel" or "movement" from one place to another;

2. Metaphors that compared learning to various types of a "solitary experience";

3. Metaphors that linked language learning to other (familiar) kinds of learning experiences;

4. Metaphors that described learning in terms of "communicating".

\section{Journey-Related Metaphors}

Learning is a self-centered experience; learning is attaining something (e.g., new knowledge, new emotional state or the destination itself).

- "Learning is acquisition"

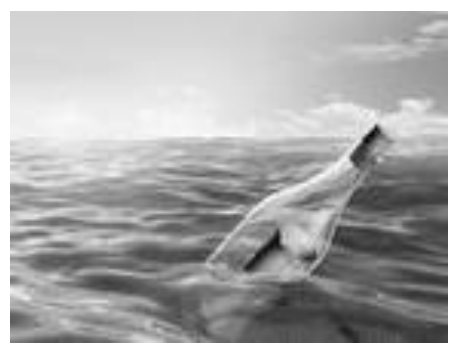

... bottle floating in the sea. It makes its journey from one shore to another.

... Ahmet falling into a deep hole. We keep wondering what will happen next and we never know how it will end.

\section{Learning as a Solitary Experience}

No reference to the important 'others';

Knowledge needs to be ingested ("eating"); knowledge is a precious possession ("mining for gold")

- "Learning is acquisition"

... eating a sour or sweet apple.

... being an ant. We need to work hard and we need strong commitment. 

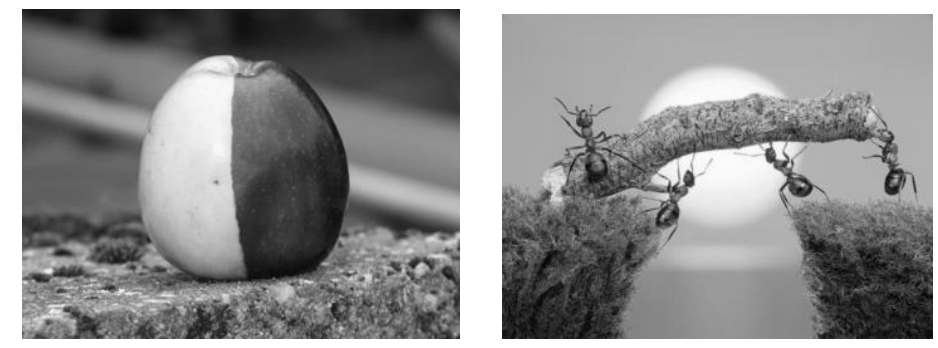

... mining gold day and night. It is so difficult and it requires a lot of energy to master the language.

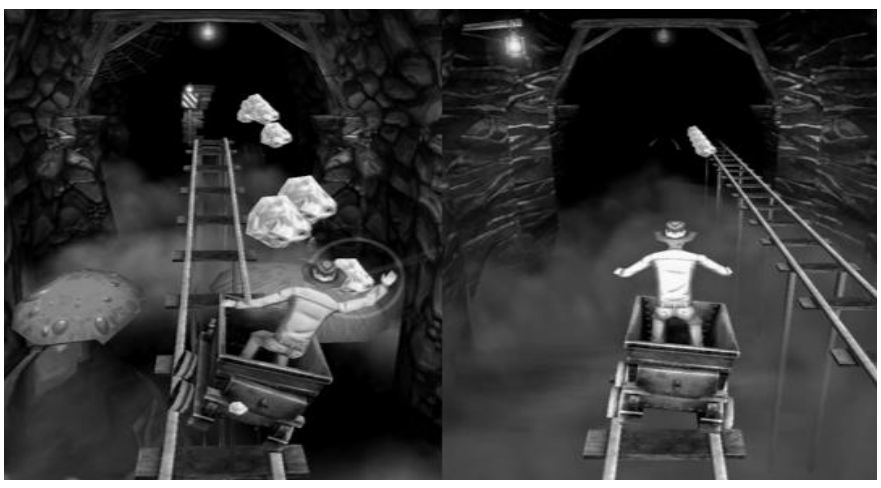

\section{Learning as a Familiar Experience}

Some metaphors showed the awareness that learning is a social act. However, these images described learning as a socially useful but essentially self-centered process

- aligned with the "learning is acquisition" metaphor.

... learning to drive. Before we know how to drive we need someone to guide us.

To be a good driver we must practice a lot.
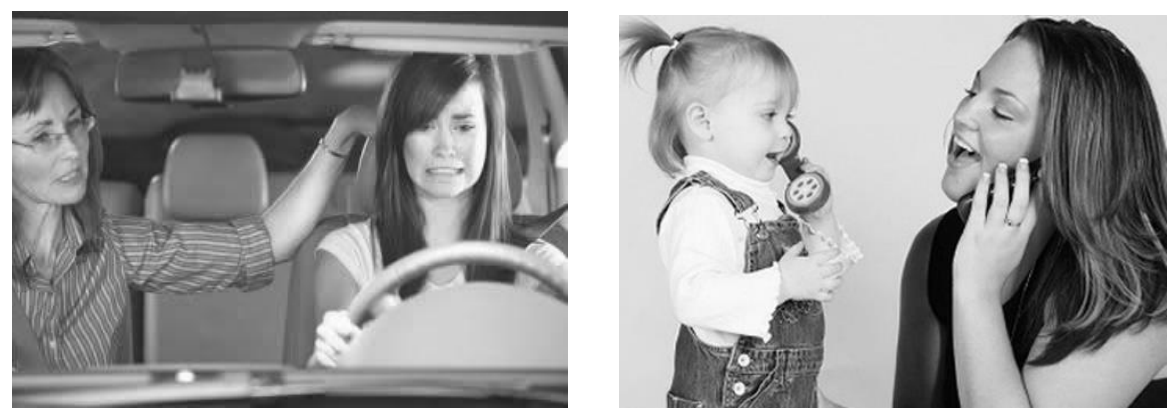

... being a kid who learns proper behaviour. We must have solid basics.

... being a child learning to talk. 
... a starting point for communicating with others. Without communication we are lonely.

... befriending a stranger. If the person is nice we want to know more about him.

... doing as the Romans do even if you are not Roman yourself.

\section{Metaphors That Described Learning in Terms of "Communicating"}

Learning viewed in terms of developing bonds between the individual and other people. Awareness of the cultural difference between the nations.

More importantly, learning involves adapting to the prevailing cultural practices and becoming "a part of a greater entity" (Sfard, 1998, p.6) as in the metaphor "doing as the Romans do".

- "learning is participation"

\section{Discussion}

Based on the use of 'conceptual metaphors', Bailey (2003) has used metaphors to elicit concepts concerning language teaching and learning. This study tries to examine the value of metaphors for students learning foreign languages by gathering experimental evidence from the student evaluation of foreign-language learning courses. Further, it explores to gather practical evidence for the value of critical thinking development, a strategy identified as useful for teachers, researchers, policymakers and curriculum developers in promoting learner autonomy.

The metaphors about learning a foreign language supported both the established "learning is acquisition" and the emerging "learning is participation" educational metaphors. However, the former metaphor prevailed. Interestingly, 10 out of 26 metaphors were journey-related. Learning as a journey is one of the oldest and most widely employed educational metaphors (Caballero, 2006; Hunt, 1976). This metaphor crosses cultural boundaries. The findings indicate a strong universal appeal and cross-cultural applicability of the "learning is a journey" metaphor.

From the learner's perspective, this metaphor embeds the connotation of the point of departure and the movement. There are 'fellow travelers', including the teacher, which implies the existence of a learning community to provide social support on one's learning route. More importantly, a journey undertaken together as a group does not preclude individual intellectual enrichment.

"Learning is a shared journey" could be a suitable platform to reconstruct the classroom reality. It can combine the "acquisition" and "participation" metaphors.

From the teacher's perspective, the "shared journey" metaphor places emphases on progress, involvement and participation. It supports practicing advanced pedagogy based on social constructivist assumptions. 


\section{Results}

Personal beliefs play a significant role in teachers' classroom practice, which are the result of their self-construction. While a conceptual metaphor program is being designed in this study, we found out that figurative language is not incidental but omnipresent in daily language. This ubiquity of metaphors and idioms is concerned with the high proficiency of figurative language. The results of the study indicate that metaphor awareness of understanding idiomatic expressions is highly significant in foreign language. Students believed that their teachers were responsible and committed to their profession. They pointed out that other than the English grammar rules, they were quite pleased with their own imaginations and preferences. While answering to the questions, the respondents interviewed mentioned that they were highly motivated about metaphors and metaphor usage.

\section{Conclusion and Suggestions}

The students participating in this study showed that they were confident using various metaphors to explain their ideas, perceptions and satisfaction levels, and to describe their feelings about their teachers, courses and personal states of mind. The metaphor strategy applied in this study provided useful feedback to the teacher in evaluating the course, instruction and students' feelings. Applying the strategy with a structured survey, students were challenged and provoked to think critically and respond reflectively to the course evaluation. The results of the study indicate that metaphor is strongly motivating. Yet, the small sample size of this study and the ambiguity of some of the metaphors suggest that there are several areas requiring further research. In particular, discourse analysis of case studies over a longer period of time is suggested. Using and collecting metaphors on a daily basis as a reflection of the lesson, focus groups after each week, month, etc. would give a deeper insight in assessing the classes daily and over a long period of time while, at the same time, affirming the use of metaphor by students as an effective and enjoyable learning strategy.

Metaphors we use reflect our thinking and feelings. Furthermore, they influence our behavior. Verbalizing and sharing the perceptions of the educational reality through metaphors provides a vantage point from where we can re-evaluate our pprevious conceptions of the educational practice. Perhaps in future we should ask ourselves when we meet in the classroom: "What will our journey be like today?" or "Are we here for work or a most glorious kind of play?"

\section{References}

Ak1ll1, M., \& Seven, S. (2010). An investigation of prospective teachers' attitudes 
towards the profession of teaching. Inönü University, Journal of Faculty of Education, 11(3), 61-73.

Balim, A. G., \& Çeliker, H. D. (2011). Prospective science and technology teachers' metaphors related to science and technology teacher concept.

Block, D. (1992). Metaphors we teach and live by. Prospect, 7(3), 42-55.

Bowman, M. A. (2007). Metaphors we teach by: understanding ourselves as teachers and learners. Retrieved January 17, 2013 from http://teaching.uchicago.edu/oldsite/pod/96-97/Metaphors.html.

Cerit, Y. (2008). Öğretmen kavramı ile ilgili metaforlara ilişkin öğrenci, öğretmen ve yöneticilerin görüşleri. Türk Ĕ̈itim Bilimleri Dergisi, 6(4), 693-712.

Çelikten, M. (2006). Culture and teacher metaphors used in educational system. Social Sciences Journal, 21, 269-283.

Fraenkel, J. R., \& Wallen, N. E. (2003). How to design and evaluate research in education (5th ed.). Boston, MA: McGraw-Hill.

Kesen, A. (2013). What lies beneath teacher beliefs? A study on metaphoric perceptions. International Journal of Human Sciences, 10(1), 1491-1502.

Kelly, G. A. (1995). The psychology of personal constructs: A theory of personality. New York: Norton.

Lakoff, G., \& Johnson, M. (1980). Metaphors we live by. Chicago: University of Chicago Press.

Lakoff, G., \& Turner, M. (1989). More than cool reason. A field guide to poetic metaphor. Chicago: The University of Chicago Press.

Marshall, H. H. (1990). Metaphor as an instructional tool in encouraging student teacher reflection. Theory into Practice, 24, 128-132.

Martinez, M. A., Sauleda, N., \& Huber, H. G. (2001). Metaphors as blueprints for thinking about teaching and learning. Teaching and Teacher Education, 17, 965977.

McGrath, I. (2006). Teachers' and learners' images for coursebooks. ELT Journal, 60(2), 171-180.

Neundorf, K.A. (2002). The content analysis guidebook. SAGE Publications, Inc.

Nikitina, L., \& Furuoka, F. (2008). Measuring metaphors: A factor analysis of students' conceptions of language teachers. Metaphorik.de, 15, 161-180.

Ortony, A., Fainsilber, L. (1989). The role of metaphors in descriptions of emotions, in: Yorick Wilks (Ed.), Theoretical issues in natural language processing (181-184. Hillsdale, NJ: Erlbaum.

Richards, C. J., \& Schmidt, R. (2002). Dictionary of language teaching \& applied linguistics. Longman Pearson Education Limited, Edinburg Gate-Harlow. Essex CM 20 2JE, England.

Saban, A. (2004). Giriş düzeyindeki sınıf öğretmenleri adaylarının "öğretmen" kavramına ilişkin ileri sürdükleri metaforlar. Türk Ĕgitim Bilimleri Dergisi, 2(2), 131-155.

Saban, A., \& Keleşoğlu, A. (2011). Bilgisayar öğretmeni adaylarının okul ve bilgisayar öğretmeni kavramlarına ilişkin zihinsel imgeleri. Kuram ve Uygulamada Eğitim Bilimleri, 11(1), 423-446.

Saban, A., Koçbeker, B. N., \& Saban, A. (2007). Prospective teachers' conceptions of 
teaching and learning revealed through metaphor analysis. Teaching and Teacher Education, 17, 123-139.

Seferoğlu, G., Korkmazgil, S., Ölçü, Z. (2009). Gaining insights into teachers' way of thinking via metaphors. Educational Studies, 3(3), 23-335.

Shaw, M., Barry, A., \& Mahlios, M. (2008). Pre-service teachers' beliefs and practices: innovations and metaphors. Paper presented at the annual meeting of the American Association of Colleges for Teacher Education, New Orleans.

Tobin, K. (1990). Changing metaphors and beliefs: a master switch for teaching. Theory into Practice, 29(2), 122-127.

$\mathrm{Xu}, \mathrm{L}$. (2012). The role of teachers' beliefs in the language teaching-learning process. Theory and Practice in Language Studies, 2(4), 1397-1402. 